\title{
Health research and market failure
}

\section{The British government needs to respond urgently to the charge that attempts to introduce an 'internal market' into the operation of the health service are undermining the country's clinical research base.}

FEw will have failed to see the irony that the Clinton administration's efforts at health-care reform, designed to increase the social spread of those able to afford adequate medical treatment, have coincided with equally controversial moves by the British government to put its own health system, long heralded as a model of universal health-care, on a more market-oriented basis. In both countries, the biomedical research community has been legitimately concerned that its own needs have not - at least initially figured high on the priority list of political reformers. And in both cases, it is becoming clear that special precautions are needed if such research is to be protected from reformers.

\section{Costly}

In Britain, these dangers have been highlighted by a report published last week by the United Kingdom Coordinating Committee on Cancer Research (UKCCCR), a body that represents the main organizations funding cancer research (see page 499). The report draws attention to a specific threat to long-term clinical trials arising from the British government's moves to put the allocation of health resources on a 'purchaser/provider' basis. The government wants to make those responsible for delivering health services (whether hospital doctors or general practitioners) directly responsible for ensuring that this is achieved in the most costeffective way. The UKCCCR rightly points out that the more such 'purchasers' are concerned with the immediate effectiveness of the services they are paying for - meaning in practice by the amount of medical care delivered to their patients - the less resources and attention they are likely to spare for long-term, communal goals needing to be addressed through research.

Two immediate responses can be made to the UKCCCR's charges. One is that public money spent on supporting the clinical trials of new drugs could be considered as a subsidy to the pharmaceutical companies that will eventually market (and profit from) such drugs, both nationally and internationally. The UKCCCR and its supporters argue that the unique research opportunities for broad-based clinical trials offered by the National Health Service (NHS) have been partly responsible for the strength of Britain's pharmaceutical companies. It could be argued that the scale of such subsidies is no longer appropriate, and that public funds would be better spent on the basic biomedical research that will produce the drugs of the future.

The second response is that there is an element of the charges that is inevitably self-serving. The changes in the NHS have, not surprisingly, generated widespread resentment among those who find they are being less generously funded from the public purse than in the past. But the government's concern to ensure that public money is effectively spent is a legitimate one. And often the most effective way of doing this is to put responsibility for it squarely on those who stand to lose most (and are also likely to complain the loudest) if this goal is not achieved. Much as researchers may resent a 'payment by results' regime, it is more satisfactory that one that makes an open-ended commitment to good ideas, however inefficiently pursued.

Yet neither counter-argument is sufficient to deny the validity of the UKCCCR's main complaint, namely that the main thrust of the government's reforms - that an internal market for health services is sufficient to provide the most cost-effective health system - is already proving severely inadequate to address the pressing funding needs of many high-value research projects. In the wider market economy, basic research is generally accepted, even by Britain's conservative government, as a 'common good' whose support is a collective responsibility. The same argument must be applied to the 'internal markets', such as those in health, which the government is so keen to encourage.

\section{Limitations}

The government's first move should be to publish as soon as possible the report it has commissioned from Anthony Culyer of the University of York, however embarrassing its criticisms of current philosophy, to demonstrate its willingness to address the problem head-on. Its second should be to come forward with proposals that demonstrate an awareness of the limitations of a market-led approach in supporting a healthy science base in the NHS, and the imagination to implement the necessary steps to improve the situation. Moves along the lines of the UKCCCR's suggested 'topslicing' of health service funds (intriguingly similar to recommendations for 'top-slicing' medical insurance contributions in the United States, as proposed by Senators Tom Harkin and Mark Hatfield and others) could be one solution. Others exist. But they each require acknowledgement of the strengths of collective action, precisely the spirit that the government is seeking to replace with its doctrine of individual responsibility. Bridging the gap is a top priority; restoring the flagging morale of health service scientists comes close behind. 